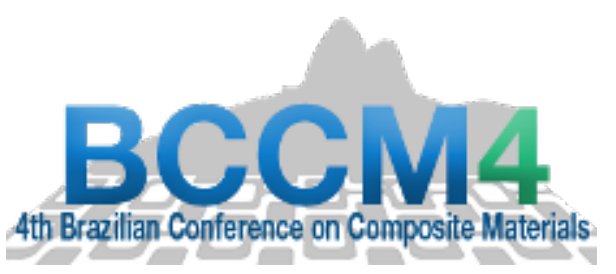

\title{
NANOCELLULOSE FILLED BIOBASED POLYURETHANE FOAMS
}

\author{
Kerche E. F. (1), Delucis R. A. (2), Magalhães, W. L. E. (3) and Amico S. C.(1) \\ (1) Department of Materials Engineering, Federal University of Rio Grande do Sul, Brazil. \\ (2) Engineering Center, Federal University of Pelotas, Brazil. \\ (3) Brazilian Agricultural Research Corporation, Forest Research National Center, Brazil.
}

https://doi.org/10.21452/bccm4.2018.11.05

\begin{abstract}
In this paper, nanocellulose (NC) dispersed in glycerin was incorporated into polyurethane (PU) biobased foams, using castor oil and glycerin, in a ratio of 3:1, as a biopolyol, produced by freerise pouring method. Firstly, the morphologicals properties, measureds by scanning electronic microscopy (SEM) images, were investigated and, after, the apparent density and compressives properties were measureds. The results indicated efficience in the preparation method for the biofoams and the filled foams presented a decrease in the cellular anisotropy and linear cell density and an increase in cell diameter, with a more homogenous cell structure. These morphologicals properties justify the modifications caused by the fillers in the biofoams, a larger cell, with less orientation, caused a decrease in the values of the apparent density and consequently lower values in compressive mechanical properties.
\end{abstract}

\section{INTRODUCTION}

Polyurethane (PU) foams are engineering materials dominant in several applications, such as industrial and domestic insulation, mattresses, upholstery, structural pieces, among others. Currently, expanded PU represents about a third of the whole PU market due to many advantages, including wide range of densities, low fragility, easy adhesion to coatings, and high versatility for production of complex shapes [1,2].

The insertion of cellulosic-based products into expanded polyurethanes may enhance some properties of these foams because of the natural affinity between NCO groups of isocyanates and $\mathrm{OH}$ groups from cellulose. Besides, the synthesis of PU foams with ingredients based on biological sources, such as plant fibers and lignocellulosic oils, has a great environmental appeal [3]. This materials was first studied in the paper of Aranguren et al. [4] in 2007, but since then, not many papers have been published. The materials already investigated as fillers include: individual fibers [5], cellulosic pulps [6,7] and wood flour [8,4].

Nanocellulosic materials have attracted considerable research attention in recent years [9] due to some exceptional properties and potential for a range of applications [10]. These nanocellulosic materials have many interesting features, such as nano dimensions (leading to high surface area per volume ratio), nontoxicity, biodegradability, biocompatibility, etc. Nanocellulose (NC) could be of interest in many fields, such as biomedical, energy, environment, reinforcement in polymer 
composites [9]. Indeed, NC is often regarded as the next generation renewable reinforcement for the production of high performance biocomposites [11].

The present study aims at obtain and evaluate the mechanical and morphological properties of polyurethane foams, using a vegetable oil added with glycerine, and compare the properties obtained with those foams with NC fillers, obtained by a simpler physical method, compared to those found in the literature.

\section{EXPERIMENTAL}

\subsection{Nanocellulose obtention}

Nanofibrillated cellulose was obtained from a bleached cellulose pulp, which was dispersed in distilled water and homogenized in a laboratory blender. Then, this mixture (3\% content) was processed between a static grindstone and a rotating grindstone, running at about $1500 \mathrm{rpm}$, and later milled (20 passes) in Super Masscoloider Masuko Sangyo mill. Through mechanical compression and shearing forces, the pulp is forced through the opening $(0.10-0.15 \mathrm{~mm})$ between the discs, and the cell wall is then individualized as a multilayer structure. Finally, the suspension in water was solvent exchanged with glycerin, using four successive centrifugations, at $3000 \mathrm{rpm}$ and re-suspended in glycerine. The final weight percent of NC in glycerin was 4\% with an aspect shown in Figure 1. The final percentage of humidity in the glycerin moisture was around $50 \%$ and it was used to manufacture the neat PU foams.

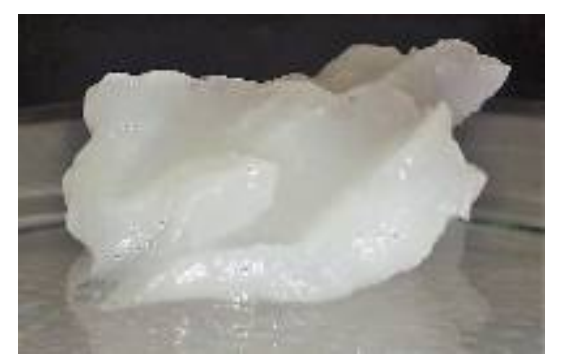

Figure 1: NC fibers (at 4\%) dispersed in glycerin oil.

\subsection{Biofoam preparation and characterization}

Biobased PU foams were prepared via free-rise pouring method and the ingredients used are shown in Table 1. Castor oil and crude glycerin PA/with NC dispersed were used at a 3:1 weight ratio as a biobased polyol. The castor oil was purchased from Ecopol Reciclagem de Polimeros Ltda. (Farroupilha, Brazil). The moisture, remaining in the glycerin with NC, acted as the blowing agent for the foam.

Polyethylene glycol, purchased from Dinâmica Quımica Contemporânea Ltda. (Diadema, Brazil), was used as chain extender. Isotane DM, purchased from Polisystem Industria e Comércio de Poliuretano (Porto Alegre, Brazil), was used as polymeric methylene diphenyl diisocyanate (MDI). Tegoamin DMEA and Tegostab B8404, provided by Evonik Degusssa Brasil Ltda. (Americana, Brazil), were used as catalyst and surfactant, respectively. All foams were made with a $\mathrm{NCO} / \mathrm{OH}$ index of 1.2 , according to the literature [1] 
$4^{\text {th }}$ Brazilian Conference on Composite Materials. Rio de Janeiro, July $22^{\text {nd }}-25^{\text {th }}, 2018$

Table 1: Formulation for the preparation of the biobased PU foams.

\begin{tabular}{cc}
\hline Component & Amount (g) \\
\hline Castor oil & 20.12 \\
NC/glycerin & 6.9 \\
Chain extended & 2.98 \\
Surfactant & 0.74 \\
Catalyst & 0.59 \\
MDI & 68.84 \\
\hline
\end{tabular}

The ingredients were mechanically stirred at $1000 \mathrm{rpm}$ for $180 \mathrm{~s}$, with exception of the MDI, which was added later to the reaction mixture, followed by extra $120 \mathrm{~s}$ of stirring. This mixture was then poured into an open mould (4.3 liters) and, after $24 \mathrm{~h}$, the resultant PU foam was removed from the mould and post-cured in an electric laboratory oven for $2 \mathrm{~h}$ at $60^{\circ} \mathrm{C}$. The foams were then conditioned $\left(65 \% \mathrm{RH} ; 20^{\circ} \mathrm{C}\right)$ for 2 weeks prior to characterization [12].

The added NC represented about $0.27 \%$ of the total foam mass. The evaluated morphological characteristics of the foam were: average cell diameter, anisotropic index (Equation 1) and linear cell density (Equation 2) [12]. The measurements were carried out using micrographs (taken parallel to the expansion direction) obtained by scanning electron microscopy (SEM) in a Jeol JSM 6060 equipment.

Anisotropic index $=\frac{(\text { Lcel-Wcel })}{\text { Lcel }}$

$L C D=\left(\frac{n \cdot M^{2}}{A}\right)^{3 / 2}$

Where: $\mathrm{L}_{\mathrm{CEL}}=$ cell length; $\mathrm{W}_{\mathrm{CEL}}=$ cell width; $\mathrm{LCD}=$ linear cell density; $\mathrm{n}=$ number of cells in the micrograph; $\mathrm{M}=$ magnification factor; $\mathrm{A}=$ micrograph area.

The apparent densities of 7 neat PU and 7 NC filled PU samples (dimensions: $50 \times 50 \times 25$ $\mathrm{mm}^{3}$, smaller size oriented in the expansion direction) were determined with the aid of a digital calliper ( $0.01 \mathrm{~mm}$ resolution) and an analytical scale (resolution of $0.01 \mathrm{~g}$ ) according to ASTM D1622. Then, the same samples were tested under compression in a universal mechanical tests machine (Instron ${ }^{\circledR}$ ), according ASTM D1621 standard. In these tests, an cross head speed of 2.5 mm. $\mathrm{min}^{-1}$ was applied to obtain the elasticity modulus and compressive strength (read at $13 \%$ deformation, according to standard), calculated according to Equations 3 and 4, respectively.

$\mathrm{Ec}=\frac{\mathrm{L} . \mathrm{T}}{\mathrm{A} \cdot \mathrm{S}}$

$\sigma \mathrm{C}=\frac{L}{\mathrm{~A}}$

Where: $\mathrm{Ec}=$ Elasticity Modulus in compression $(\mathrm{Pa}), \sigma \mathrm{c}=$ Compressive strength $(\mathrm{kPa}) ; \quad \mathrm{L}=$ Load $13 \%$ of strain $(\mathrm{N})$; $\mathrm{T}=$ thickness of the sample $(\mathrm{m}) ; \mathrm{A}=$ Cross sectional area $\left(\mathrm{m}^{2}\right) ; \mathrm{S}=$ Extension (m). 


\section{RESULTS AND DISCUSSION}

Appropriate surface quality, for the both foams, can be observed in the optical microscopy images (80×) (Figure 2). A stronger yellow color was also observed in the foams with NC, due to the incorporation of the filler, as already reported in the literature [1].
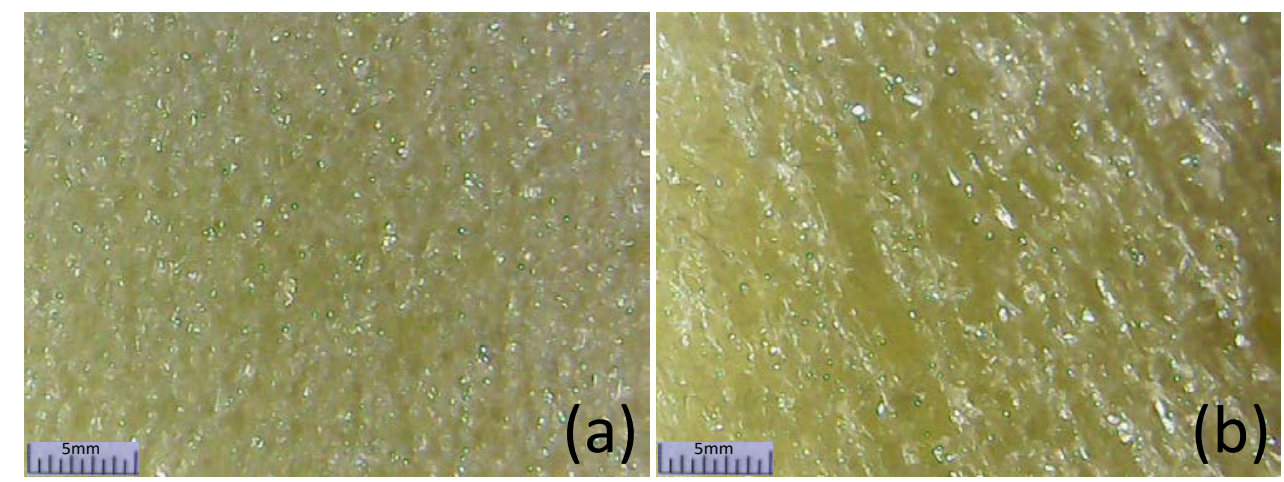

Figure 2: Images for neat PU (a) and NC-filled PU (b) biofoams.

According the micrographs, for the neat PU foam (Figure 3 (a)), can be observed a smaller and more heterogeneous microcellular structure, composed of smaller and an apparent greater number of open cells with a more elliptical shape, oriented in the direction of expansion. This greater number of open cells, of the neat PU, may be due to the more vigorous reaction of the foam, which may cause a higher degree of expansion and, consequently, disruption of adjacent cell walls. Comparatively, the PU-NC foam, shown in Figure 3(b), appears to have larger number of circular cells, probably due to the lower reactivity and expansibility, atributted to steric hindrance caused by the fillers, during polymerization. Besides, for PU-NC, there was slight deposition of the reinforcement inside the cellular wall, this effect indicates an optimal affinity of the NC-PU system, as reported in the literature for cellulose-filled foams [3].

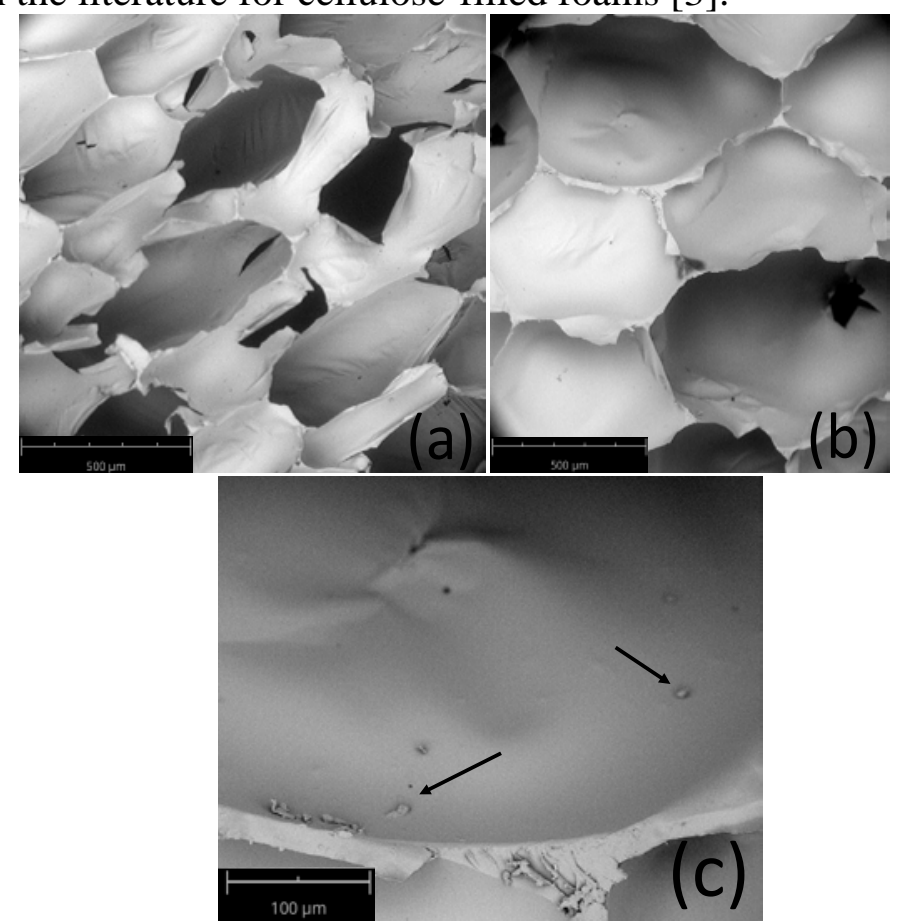

Figure 3: SEM microscopies for neat (a) (150×) and PU-NC filled (b) (145×), (c) (450x). 
The filled foams presented a typical decrease (around 60\%) in anisotropic index (Figure 4 (a)), attributed to the steric hindrance, caused by the presence of fillers, during polymerization. The filler increases viscosity and hampers flow of the foam, during expansion, as reported in the literature [7]. The PU-NC foam also presented a statistically significant increase in cell diameter (around 30\%) (Figure 4 (b)) and a decrease in linear cell density (around 160\%) (Figure 4 (c)). These results corroborate with those observed for the micrographs, where, for the foams with NC, a larger cell is observed and consequently fewer cells occupying the same space. This effect was contrary to previous studies on PU filled foams, with particles and vegetable fibers [7, 14], and can be attributed to the reduced filler dimensions, which may promote the formation of crosslinks, between NCO groups from isocyanate and $\mathrm{OH}$ groups from the cellulosic fillers.
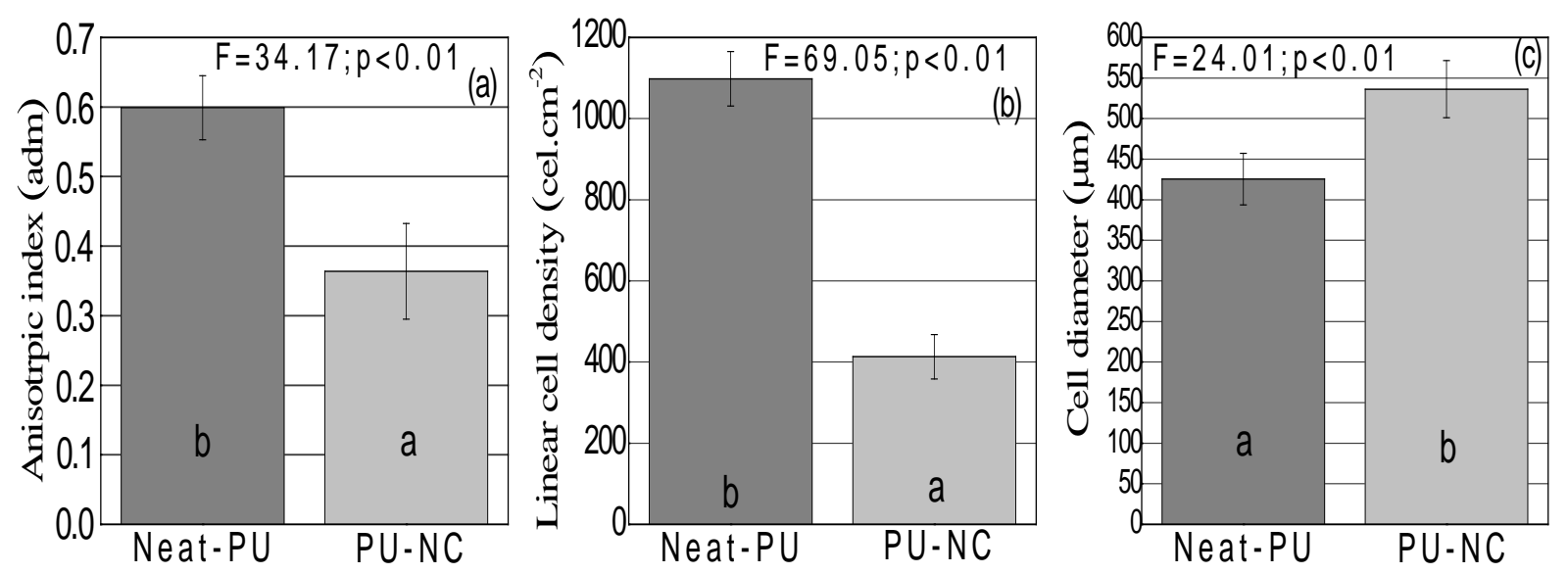

Figure 4: Morphological properties of neat-PU and PU-NC biofoams.

The larger cell size of the foams with NC, led to a smaller amount of material for the same volume and, therefore, there was a statistically significant decrease (around 100\%) in the aparent density (Figure 5 (a)). The largest cell diameter of foams with NC has affected directly on this property, since larger and more voluminous pores carry greater volume of air, justifying, also, the lower values of resistance and modulus (Figure 5 (b), (c)). However, when the results on specific resistance (Figure $5(\mathrm{~d})$ ) are observed, the properties for the neat and NC PUs are statistically the same. These results can be attributed to the higher structural stiffness, caused by the presence of the NC, that act as nucleation sites and enable a possible chemical tie with NCO groups of PU. Besides, factors that influence this property can be attribuated, including the filler content and type, wich provide competing and sometimes opposing polymerization mechanisms. 

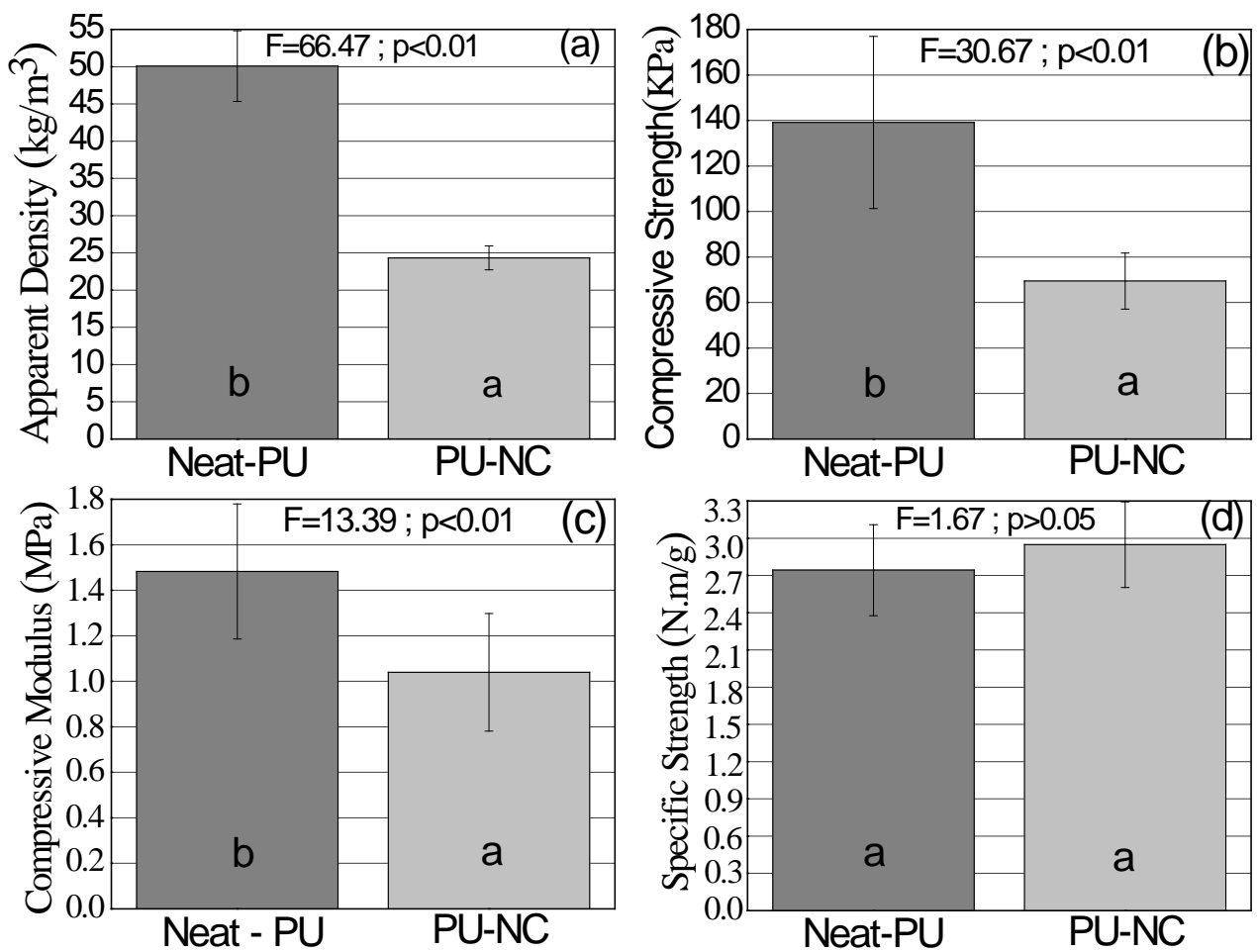

Figure 5: Apparent density and compressive mechanical properties of PU foams.

\section{CONCLUSIONS}

Rigid polyurethane foams were succefull obtained, utilizing a vegetable oil added to glinerine as biopolyol, presenting a good aesthetic surface. Besides, the NC fibers dispersed in glycerin oil were successfully used as fillers, presenting good compatibility with the PU system. Although the low rise of the fillers in the foam, there was a decrease in anisotropic index and formation of larger and more rounded cells with a filler accumulation on the polymer cellwall, according the SEMs images. These effects caused a decrease in the density, for the foam with fillers, and justify the lowers results in compressive strength and modulus. Besides, the results for specific properties did not present statistical alterations, probably related to the higher structural rigidity of the PU-NC. All results in this work follow those reported in the literature, for filled foams.

\section{ACKNOWLEDGEMETS}

The authors would like to thank CNPq for the doctorate grant.

\section{REFERENCES}

[1] DELUCIS, R.A.; MAGALHAES, L.W.E.; C.L. PETZHOLD; S.C.AMICO, 'Forest-based resources as fillers in biobased polyurethane foams', Journal of Applied Polymer Science 135 (3) (2018) 45684.

[2] DELUCIS, R. A.; MAGALHAES, W. L. E.; PETZHOLD, C. L.; AMICO, S. C., 'Thermal and combustion features of rigid polyurethane biofoams filled with four forest-based wastes', Polymer Composites DOI 10.1002/pc.24784 . 
$4^{\text {th }}$ Brazilian Conference on Composite Materials. Rio de Janeiro, July $22^{\text {nd }}-25^{\text {th }}, 2018$

[3] DELUCIS R. A.; PETZOLD C. L.; AMICO S. C., 'Resíduos florestais como reforço em espumas rígidas de poliuretâno' in 'Congresso Brasileiro de Engenharia e Ciência dos Materiais', Proceedings of a national conference, Natal, RN, Brasil, November, 2016, 4508-4519.

[4] ARANGUREN, M. I.; RÁCZ, I.; MARCOVICH, N. E., 'Microfoams based on castor oil polyurethanes and vegetable fibers', Journal of Applied Polymer Science 105 (5) (2007) 27912800.

[5] GU, R.; SAIN, M. M.; KONAR, S. K., 'A feasibility study of polyurethane composite foam with added hardwood pulp.’, Industrial Crops and Products 42 (1) (2013) 273-279,.

[6] SILVA, M. C.; TAKAHASHI, J. A.; CHAUSSY, D.; BELGACEM, M. N.; SILVA, G. G. 'Composites of rigid polyurethane foam and cellulose fiber residue', Journal of Applied Polymer Science 117 (6) (2010) 3665-3672.

[7] GU, R.; SAIN, M. M., 'Effects of Wood Fiber and Microclay on the Performance of Soy Based Polyurethane Foams’, Journal of Polymers and the Environment 21 (1) (2013) 30-38.

[8] MOSIEWICKI, M. A.; DELL’ARCIPRETE, G. A.; ARANGUREN, M. I.; MARCOVICH, N. E. 'Polyurethane Foams Obtained from Castor Oil-based Polyol and Filled with Wood Flour', Journal of Composite Materials 43 (25) (2009) 3057- 3072.

[9] MONDAL, S; 'Preparation, properties and applications of nanocellulosic materials', Carbohydrate Polymers 163 (1) (2017) 301-316.

[10] DONIUS, A. E., LIU, A., BERGLUND, L. A., \& WEGST, U. G. K. 'Superior mechanical performance of highly porous, anisotropic nanocellulose-montmorillonite aerogels prepared by freeze casting' Journal of the Mechanical Behavior of Biomedical Materials 37 (1) (2014) 88-99. [11] K. Y. LEE, Y. AITOMÄKI, LARS A. BERGLUND, K. OKSMAN, A. BISMARCK 'On the use of nanocellulose as reinforcement in polymer matrix composites’, Composites Science and Technology 105

(1) (2014) 15-27.

[12] ARANGUREN, M. I.; RÁCZ, I.; MARCOVICH, N. E. 'Microfoams based on castor oilpolyurethanes and vegetable fibers', Journal of Applied Polymer Science 105 (5) (2007) 27912800.

[13] ZIMMERMANN, M.V.G.; DA SILVA, M.P.; ZATTERA, A.J.; SANTANA, R.M.C. 'Effect of nanocellulose fibers and acetylated nanocellulose fibers on properties of poly(ethylene-co-vinyl acetate) foams', Journal of Applied Polymer Science 134 (1) (2017) 44760.

[14] NAR, M.; WEBBER, C.; ANNE D'SOUZA, N. 'Rigid polyurethane and kenaf core composite foams’, Polymer Engineering \& Science 55 (1) (2015) 132-144. 